\title{
Digital Legacy: Designing with Things
}

\section{Dr Stacey Pitsillides}

School of Design, University of Greenwich, London, United Kingdom

s.o.pitsillides@greenwich.ac.uk

Dr Stacey Pitsillides is a Lecturer in Design in the School of Design, University of Greenwich. Her research considers how technology and design shift our understanding of death and bereavement. As part of this research she has curated events for public engagement that question legacy and aesthetics through artistic research, co-design and situated design. In addition to this she is on the standing committee for the Death Online Research Symposium and has been the co-facilitator of three unconference events discussing issues of death and digitality.

Website: http://www.digitaldeath.eu/ [@RestInPixels] 


\title{
Digital Legacy: Designing with Things
}

\begin{abstract}
This paper explores how theories of things can create new forms of agency for the dead. It considers how meaning is constructed through the use or translation of our diverse collections and environments online. These memorials and rituals offer a plurality of narratives, experiences and aesthetics, which have the potential to give a wider scope for constructing a durable biography after death. The paper draws conceptual links between digital and physical materials and aims to expand interdisciplinary discourse around the way design can create new forms of legacy through rethinking the role of digital things in our lives.
\end{abstract}

Keywords: design, digital legacy, things, agency, narrative

\section{Designing Things}

Contemporary design methods are uniquely placed to contribute to the development of new rituals and practices around death and bereavement. This paper explores how the things that designers and people make have the agency to construct social relations and networks. These relations and networks are activated in new ways after death. By focusing on various forms of agency through what is left behind or translated within the bereavement process, this paper analyzes how digital, physical and hybrid things become actants, providing the reader with a number of examples and case studies. These examples show how agency is imparted collectively through human and non-human actants, extending their legacies and shifting the role of the dead within these networks.

It expands on previous research that has analysed the social relations constructed between the bereaved and dead through social media (Giaxoglou, 2014; Klastrup, 2015; Irwin, 2015) and research that explores how rituals and practises may be expanded through designing things that blend physical and digital interactions (Wallace \& Press, 2004; Moncur \& Kirk, 2014; Karana, Giaccardi, Stamhuis, \& Goossensen, 2016). Additionally, it considers 
how bereavement from a constructivist perspective (Neimeyer, 2005) recognises the role the dead play in our lives and our continuing bonds ${ }^{1}$ with them.

As design has been opened up beyond the world of products and has begun to intervene and work within systems under labels such as service designer, experience designer and co-designer, the idea of "designing for a purpose" (Sanders \& Stappers, 2008), that puts emotion and experience at the centre of the design, is becoming an established goal for a range of companies and services. By enacting a process of making, design shifts networks. It creates fluid possibilities through changing aesthetics, environments and the way that people engage with them.

However, designers do not always see how the things they make affect people. Kimbell and Street (2009) chart this struggle between designers and the things they create by analysing the themes and contradictions within the terms design and design thinking (p.6). These differences stem from whether you focus on an understanding of people's relationship to things or on things in terms of their processes of construction. Friedman and Stolterman (2014) also claim that one of the challenges for the convergence of design practice and research are the "increasingly ambiguous boundaries between artifacts, structure and process" (Friedman and Stolterman, 2014: viii). This is particularly true online where data, artifacts, processes, networks and database structures are more visibly intermingled.

Latour (2008) provides a useful context for understanding how design has shifted towards designing within a network where the things we make open up new understandings that include the "very substance of production," which have expanded "from the details of

\footnotetext{
${ }^{1}$ Continuing Bonds theory states that after a person dies, the relationship is not severed but continues and evolves after death. It critiques Freud's (1922) emphasis on the necessity for the bereaved to engage in time limited grief work, which includes coming to terms with the loss, and moving on to form new attachments. In continuing bonds the relationship is renegotiated rather than detached from - continuing as guidance, shared values and advice that become a valued part of the survivor's own personal biography (Marwit \& Klass, 1995; Klass, 2006).
} 
daily objects to cities, landscapes, nations, cultures, bodies, genes, and ... nature itself” (Latour, 2008: 2). Latour claims that through this redefinition design has the potential for turning objects into things by promoting them as matters of concern. The use of the term things as a theoretical framework allows for an exploration of the agency of the dead through what is left behind or translated within the bereavement process.

Things allow designers to consider the permeable state between subjects and objects. Creating an intersection between personhood and thinghood (Ingold, 2013: 94), where things can create people (Miller, 2008) but may also be used as a tool to think with (Henare, Holbraad, \& Wastell, 2007; Turkle, 2011; Malafouris, 2013). Thing theory is a philosophical branch, grown from Martin Heidegger's (1971) mediations on the entomology and categorisation of things as opposed to objects. Considering the example of a jug as a potential thing, Heidegger claims it is the making that "lets the jug come into its own. But that which in the jug's nature is its own is never brought about by its making. Now released from the making process, the self-supporting jug has to gather itself for the task of containing" (p.166).

Heidegger makes a distinction between the making of the jug and its nature to contain liquid. For designers it is this question of the nature and fluidity of digital things that make them interesting to consider within this framework. By broadening things to explore them as an assembly or gathering they become relations, so digital things (like Facebook) may also contain people. This is important to the field of design, as the understanding of things as a gathering challenges the design community to open up to a wider social engagement of how the things they make construct social relations and networks (Telier, 2011:2) that may be activated in new ways after death.

\section{Does Death Change Things?}

Brown (2004) claims that we are confronted with the thingness of an object, in particular, when an object stops working for us. He gives the example of the car that stalls or the 
window that gets filthy but this could also be exemplified in the Facebook page that continues to have a birthday after someone has died or the answerphone that still holds the person's voice after death. These irregularities promote different modes of thinking through things and being through things (Henare et al., 2007) that construct new forms of agency that are activated in specific ways when a person dies and is missing from the network. The missing person changes the nature of the network and in particular the specific profile, its thingness which is translated from a social container to a memorial container.

Taking the example of a Facebook profile asking you to reconnect with someone who is dead, the notion of agency is questioned. When a dead person's profile acts as a living person's profile it is acting within the coded framework of Facebook as a database but socially this is misplaced, as the dead should not be asking to communicate with us. Therefore, Facebook as a network for the living and the dead chose to shift the nature of their system of categorisation by defining what interaction with the dead should look like. In 2010 this led to the Memorial Mode $^{2}$, which limited the features of dead accounts, and aimed to solve this problem of the dead having agency by defining them as dead.

Garde-Hansen (2009) claims that social media is designed to follow someone else's database structure and logic. Aesthetically it also does not necessarily speak about individual people. In most social media profiles there is no easy way to locate or search explicitly for specific moments and memories, making it both emotional and time consuming to reflect on their meaning. However, Kasket (2012) shows how this actually functions in practise through her interviews with administrators of Facebook memorials by considering how their use of "you" to address the deceased's profile has created more tangible forms of communication with the dead. Through the specific structure and form of time-delayed responses social networks users are negotiating, constructing and co-constructing durable digital biographies

\footnotetext{
${ }^{2}$ Facebooks query page (the legacy contact was introduced in 2015): https://www.facebook.com/help/1506822589577997 [accessed: 26 May 2018]
} 
for their loved ones (Walter, 1996; Walter, Hourizi, Moncur, \& Pitsillides, 2012) in an ad-hoc way. So although the company who designed the structure of these social media accounts did not consider this specific function in the original design, the memorial becomes an actant (Latour, 2005: 52-54) which functions to extends the agency of the dead.

The Facebook page is distinctive when compared to websites and memorial pages designed specifically for digital assets and memories (Romano, 2011). It already has a community present and is used in a similar way in death, as in life, for direct communication with the person whose profile it is. There is also a digital tangibility to writing on social media. Kasket's interviewees (p.66) expressed a feeling that Facebook could get their messages to the dead. It is this agency that is imparted digitally through the system of writing on walls, in which a response is normally either delayed or not given.

The page that was once a centre of communication from you becomes a source of communication to and about you. It feels like an access point. We continue to perform the same action after death as we did in life. We sit down at our computer, write a message and click send. This does not require a two-way action to feel complete (Harper, 2010). After all we are used to waiting to receive a response, sometimes days or months later. We feel we are heard. In this way, digital content has the potential of actually growing rather then diminishing a person's entity after death and adding another chapter to that person's life.

Walter (2013) claims that the dead have always possessed agency through "wills, philanthropic trusts, genealogical surprises, reincarnation, and even ... through the very materiality of the dead body itself' (Walter, 2013: 21). Schwartz (2015) expands this discourse around the dead body by stating that "attending to the corpse as a thing opens up a theorization of the material substrate of communication" (p.2). She explores how the dead's agency is technologically and socially mediated through a range of actants, making the embalmed body of Eva Perón, for example, the body of the nation (p.27). 
Latour (2005) defines agency as the capacity for an actor to perform in a way that affects a given environment or situation. Agency is also used as a way of critically reflecting on what digital things do and therefore must be both visible and describable in order to be used as a form of analysis. This takes into account Ingold's (2013) positon that things are extended through their use and 'possessed by action' in a way that incorporates the liveliness of materials and things. These things are 'forever immersed in action' and so entangled that they cannot be traced back to a point of origin (p.96-97). These explorations of agency show how the intersection between specific actants (human and non-human), material qualities and interactions can give new functions to a network.

These networks also include material actants or physical devices, e.g. a mobile phone. In their ethnographic study, Odom, Harper, Sellen, Kirk, \& Banks (2010) present one account of a mobile phone being buried with the deceased as a means of communication, used functionally to pass information to the deceased, such as the football scores of their favourite team. The phone is used in a very similar way as people writing to their loved ones on social media (Brubaker \& Hayes, 2011; Getty et al, 2011) and there is a tangibility in performing the act of communication through a device, computer or phone. The process of burying a phone becomes a new ritual that gives the device a functional role in continuing bonds between the living and dead and becomes a key actant in this communication network.

The following case studies show how it is through the use, creation and appropriation of legacies that things come to matter. By considering the way that academics use design interventions to help us to rethink our relationship to digital legacies. And designers alongside the public show how legacies can be creatively expanded within a range of digital networks. This paper seeks to demonstrate the plurality of agency in the digital age and the role designers play in creating new approaches to legacy and biography. 


\section{The Intangible Inheritance}

Stories play a role within design research as they provide a context and focus for how design intervenes in networks. I am considering my grandma's thimble collection as a biographical narrative (Pitsillides, 2017: 45) similar to Walter’s (1996) ‘durable biography.' In 1996

Walter tells the story of how the loss of his father, and the practises that emerged during his funeral, created an entanglement between himself as a researcher and the social and material circumstances of his own bereavement that allowed for new reflections on the nature of grief. My grandma's thimbles also become a mode of analysis to expand on the agency of things and the role that meaning has in supporting these things to form a network. Margit Neisig (2014) describes this use of design methods in new contexts as a form of translation. This initiates networks that negotiate between human and non-human actors to establish new common meanings.

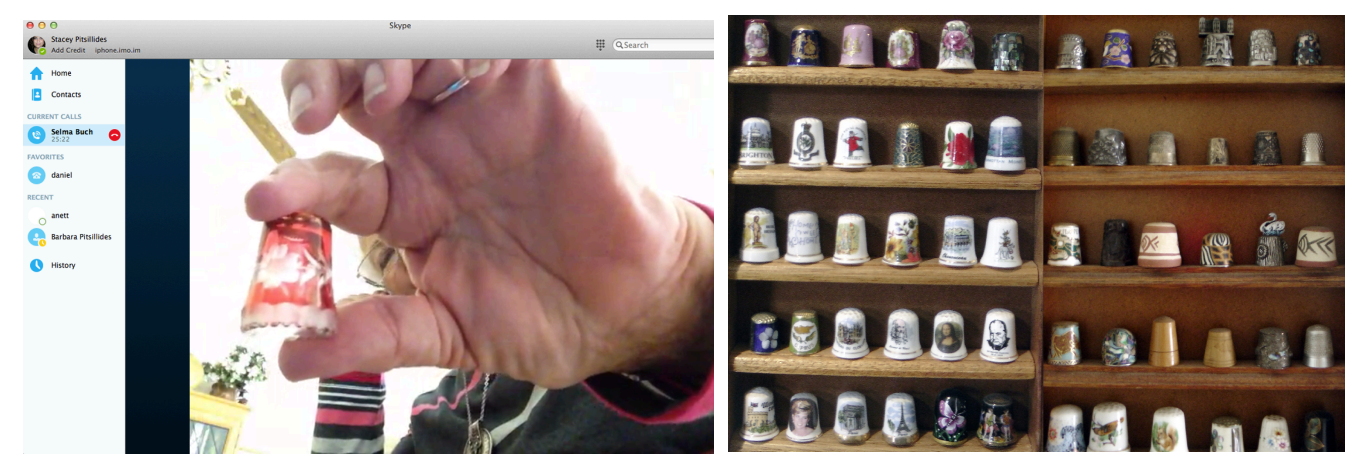

Figure 1: My Grandma, in Johannesburg, showing me on Skype one of the glass thimbles she acquired in Germany (left) and one of her thimble trays (right).

The narrative of my grandma's thimbles are interwoven with her own identity. They are small contained things, easy to overlook as they make up the background or environment of a person's home. At the same time, we may begin to unconsciously think of the thing and person as synonymous. It would be a mistake to limit the exchange and excitement in the process of collecting and discussing the meaning of this collection by saying that, if my grandmother passed away, the role of the thimbles in my life would be to symbolise or signify my grandmother. This is to undervalue the thimbles themselves, to diminish them to 
the point of a virtual symbol, as something that is only standing in for something else that is no longer here. It does not take into account the agency of the things themselves and how their use within my environment would keep her presence in my life.

If we look to the work of Daniel Miller and his understanding of the way 'stuff' creates people (2010), it would be truer to say that the thimbles are an extension of my grandma, as they hold her experiences and are used functionally as non-technological memory devices. Yet it is through the shared narrative and listening deeply to my grandma describing her collection that these things develop agency that transforms them into matters of concern that need to be cared for (Latour, 2004; Latour, 2008). This narrative does not need to prove why they matter or necessarily define what they mean, as long as it explores how they can be used and their nature. A new narrative emerges through the thimbles. They become a specific telling or biography of my grandma. This helps us understand the significant role that things play in our lives, placing them on the same level as social engagement with people (Miller, 2010). By paying attention to the thimbles, taking on their meaning and offering to become their custodian, I am removing the precarity of their existence after their previous collector's death and the potential burden of inheriting them from the rest of the family (Odom et al., 2010).

\section{Legacy: the Physical, the Digital and the Hybrid}

In today's society we are increasingly living with blended collections of physical, digital and hybrid artefacts (Kirk \& Sellen, 2008), which hold a wide range of meanings and sentimentalities. We may have special e-mails, digital photographs, music or artwork on our computers in addition to material artefacts that comprise a whole range of things. Massimi and Baecker (2010) consider the ways in which we use technology to remember the dead and how this allows for personal reflection on our own digital estates. 
The inclusion of technology into the things we inherit is not as straightforward as inheriting tangible items (such as clothes or jewellery). This is because practices surrounding the inheritance of data and digital assets are still developing and there are not the same social, cultural or religious guides as to how this should be approached or dealt with. In their survey, Massimi and Baecker (2010) showed that a majority of people had never thought about how they wanted their own digital estate to be handled but at the same time were using their computer and the internet to help them remember, commemorate, or reminisce about their deceased family member.

In broad terms, the things we keep that become sentimental do so for a range of idiosyncratic reasons, which cannot be fully defined. Focusing once again on the example of the thimbles, it would be easy to think of them as fitting the criteria of sentimental things. They are small, made of a range of materials and have a strong link to the body. They talk of histories; both in terms of the things themselves protecting the fingers whilst sewing and darning, but also the history of my grandma's life. However, despite this rationale, the thimbles do not conform. In fact, they inspire quite the opposite reaction, in the sense that the family do not value them due to their material and aesthetic qualities.

As a designer I see the potential here for the thimbles to be digitally augmented; either via linking them together or by adding extra content about their stories, how they were acquired or where they come from. This augmentation would create a new context to extend their presence across the family and even create links among those physically distant in a personal way. The fact that digital things can keep a person's legacy intact while still being separate and somehow parallel from our own lives is quite compelling. However, there are also questions of authenticity: Do we place more value on an exact copy or on an edited collection of digital possessions? 
If we do wish to have an edited collection of digital possessions, important questions need to be raised such as: who takes over this editorial role when someone dies; who decides whether things are left or deleted, translated or preserved; and what impact does this have on the community (family or wider networks). Therefore, depending on the thing and the community using it, the addition of digital content or even full digitalisation may actually have the potential to increase the meaning of the original and contextualise its place in people's life.

But if materiality does play a role in the way we respond to things emotionally before we even see their contents, then I would argue that we must understand the properties of the digital as a material (McCullough, 1998; Lange-Berndt, 2015). Karana, Giaccardi, Stamhuis, \& Goossensen (2016) have expanded this discourse of crafting digital content. They present an approach to material experiences that incorporates digitality in sensorial, affective, interpretive and performative ways. If the things we collect are informed by experience, memory and materiality - where materiality includes the consideration of digital data as a specific material of linguistic, sonic, pixel and temporal structures - then these structures can be crafted and enmeshed with physical materials designing new rituals that incorporate digital elements creating alternative forms of agency for the dead.

\section{Designing Rituals that Blend Physical and Digital Materialities}

Jayne Wallace has explored the role of empathy, beauty (Wallace \& Press, 2004) and enchantment (McCarthy, Wright, Wallace, \& Dearden, 2006) through digital jewellery (Wallace, 2007). Her work contextualises the role of crafts and aesthetics in relation to current trends in functionality and gadgets. It is the ability of the things she creates to engage with us emotionally that pushes them beyond the gadget and develops new approaches to crafting in the digital age. She argues that craft has always situated itself technologically. By opening up craft and making to the digital, we are able to create new experiences. That 
blends the characteristics of digital: temporality, interaction, sensory with handmade, sentimental or historical things. Richardson (2005) supports this by considering "craft in terms of attitude toward material, humanity, and environment" (p.157). He applies this to digital and physical artefacts concluding that makers with a proficiency in digital systems and ethics allow the digital to be crafted.

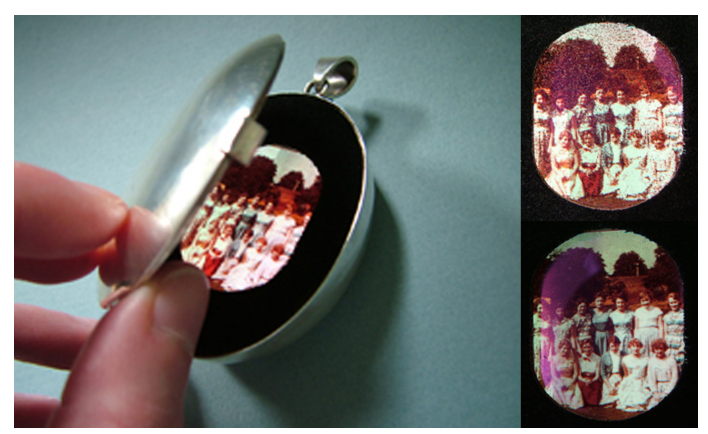

Figure 2: Jayne Wallace's "forget" digital locket, part of the Unpicking the Digital series (2010). This series explores notions of memory, loss and our relationship to digital technologies. See: Jayne Wallace's Portfolio - A locket that can Forget. [ONLINE] Available at: https://www.jaynewallace.com/a-locket-thatcan-forget. [Accessed 16 July 2018].

The digital locket 'forget' is a good example of this. By using the form of the locket people are able to understand its historical function and expect that hidden internally is a precious photograph. The digital locket extends this functionality by including an element of interaction, in which the photograph decays by a small amount every time it is opened until eventually fading away. The digital adds a new dimension between the human and the thing. By opening it, you affect it and are thus entangled. This function shifts the value of a singular digital photograph, as one must consider how accessing it will make it decay. Therefore, the nature of the thing is to encourage human restraint and the memory of the photograph. We are able to think through the closed locket and question our relationship to the prevalence and value of digital photography.

This shows the need for developing a better understanding of what we should do with digital things, where "despite the culturally prevalent 'disposable technology' paradigm, and the idea that the data may matter more than the substrate it is stored on" (Massimi \& Baecker, 2010: 5) we need to consider further how we interact and experience data which moves beyond our current technical systems and devices. It is clear that communication technology can enhance the agency of the dead (Walter, 2008; Ellis Grey, 2012) but the ways in which it 
does so are multifaceted. When our experiences of digital artefacts differ so much that some people feel little or no reaction and others liken their inherited mobile phone or laptop to jewellery due to its presence on the body (Massimi \& Baecker, 2010). This exemplifies the fact that any design intervention needs to engage both the person and the thing as a relation and consider where the meaning is situated.

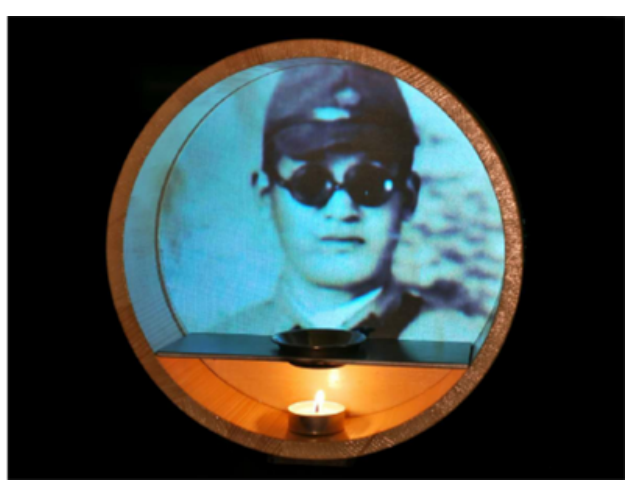

Figure 3: Uriu, D., \& Okude, N., (2010) ThanatoFenestra: photographic family alter supporting a ritual to prey for the deceased.

ThanatoFenestra (Uriu \& Okude, 2010) is another ambiguous object whose thingness we may explore. It is a digital memorial that uses the qualities of digitality to play with the traditional rituals and materials of a Buddhist home shrine. A minimal interaction causes the projected image of the deceased to flicker with the movement of the candle, that may just about catch our eye. This movement causes us to question the root of such agency and animation of the dead ancestor e.g. are they flickering to let us know they like the position we have placed these flowers? The material and digital communicate with each other. The candle, wind and digital interface are in correspondence (Ingold, 2013) and the humans dip in and out of this, alluding to the spiritual nature of communicating with the dead.

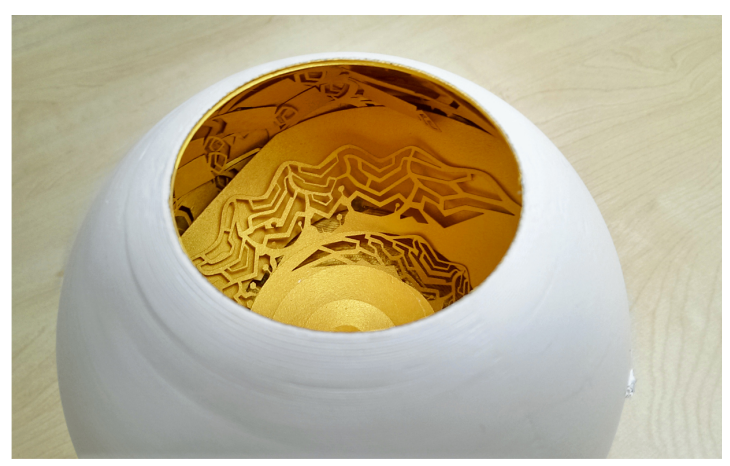

Figure 4: Moncur, W., Julius, M., Van Den Hoven, E and Kirk, D. (2015) Story Shell. Photography: Miriam Julius. 
Moncur and Kirk (2014) also consider the material properties of digitality identifying when memorials should be designed as physical, digital or hybrid. They constructed a bespoke memorial called Story Shell (Moncur, Julius, Van Den Hoven, \& Kirk, 2015) that reflects the environment and symbols associated with a person's life. Unlike the previous two examples, it is not an augmented existing artifact but contextually references a shell in terms of its form and function. The memorial contains audio stories that are activated through cupping it. There is a tactility evoked through sharing moments with it, as it responds to you constructing a listening space.

There is also an exchange of agency at play with the Story Shell, in the sense that it is fed with stories and animated through touch, whereby the recorded stories are played back. Neither human nor object could be complete without the interaction and it is this relationship that promotes us to consider its thingness. Unlike ThanatoFenestra though you must have a desire to listen to the stories in order to use it. This makes the thing itself less active in the relationship, like the photo album its primary function appears to be storage of the precious memories. Therefore, it is unclear whether this extends the agency of the dead or if it is in fact an extension of the person using it. So the creation of a bespoke memorial does not necessary extend the agency of the dead but instead may become embedded in the bereavement as a form of reflective interaction.

\section{Embedded Memorials: Creating and Subverting Death Online}

Online there are also many examples of people responding to bereavement through virtual memorials in personal and individual ways (Haverinen, 2014). Gaming platforms have been known to use the particular structure, environment and context of the game in which they knew that person to develop these memorials (Walter et al, 2012). This has been particularly relevant in Massively Multiplayer Online Role-Playing Game's such as Eve Online and World of Warcraft. Here, appropriate memorials have been constructed to reflect not only the 
nature of the deceased but the affordances and codes of these specific gaming platforms (Gibbs et al., 2013), extending the agency of a specific game character with everything from in-game rituals and statues to roadside memorials.
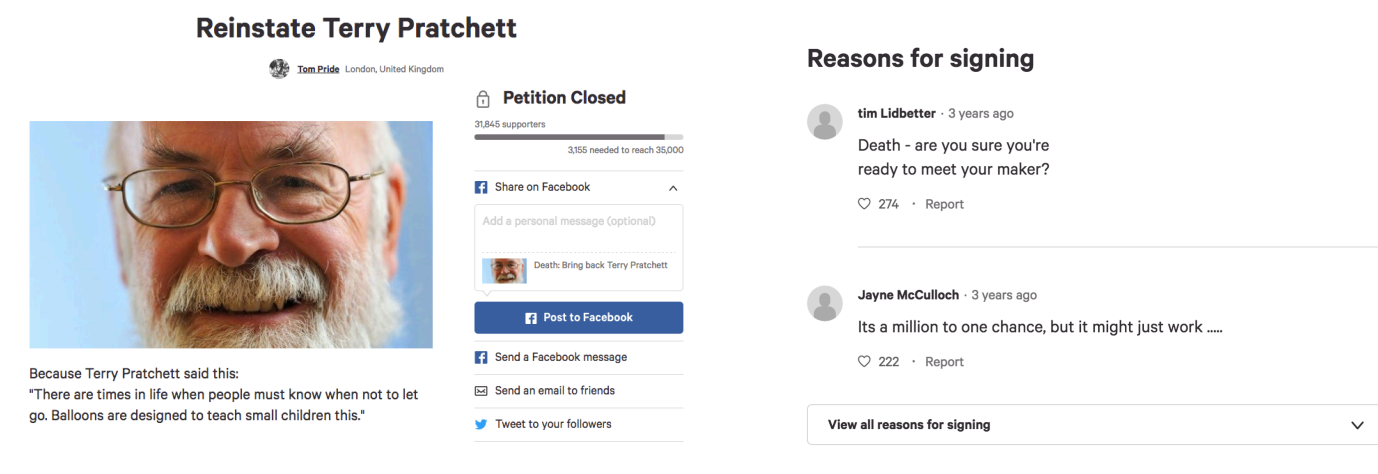

Figure 5: Screenshots of change.org campaign "Petitioning Death: Reinstate Terry Pratchett" [2016] https://www.change.org/p/death-bring-back-terry-pratchett [Accessed: $15^{\text {th }}$ May 2018]

Petitioning Death: Reinstate Terry Pratchett can be considered as a specific case for exploring how digital things can be subverted to craft a materially driven durable biography (Walter, 1996). This ad-hoc memorial uses the structure and function of the campaigning site change.org, commonly used to start campaigns and contribute to grass roots activism, to create a fitting memorial for the author Terry Pratchett who died in March 2015. Terry Pratchett, author of the Discworld series, created the character Death and gave him a sense of humour and many human-like qualities. This change.org campaign extends the agency of the fictional character Death allowing him to become an embedded actant within this petition.

This allows Death to be possessed by action (Ingold, 2013) with users redefining the nature of the site through the construction of a petition as a memorial. As a serious site for political activism it formalises the arrangement of writing to Death and creates a tangibility to the memorial, which highlights the humour of Terry Pratchett alongside his political satire within the Discworld series (Duncan, 2008). The fact that the petition closed with 31,845 signatures is further evidence of the agency of the site as an actor. An element of unintended humour is added by change.org as the site automatically increases the goals set in order to 
prompt more signatures to be added. The target increased from 5,000 to 35,000 as more people signed up. This could be seen as Death making sure that the mortals could not get the better of him as the petition closed just short of its goal. People could both sign the petition and contribute a personal reason e.g. "Death - are you sure your ready to meet your maker?" This collective activity constructs a biography that is assembled through the materiality of an online network and functions to enmesh Terry Pratchett in his fictional universe Discworld after death.

The digital medium can also be used to design and build entirely new platforms of collective ritual, as is the case with The Johnny Cash Project ${ }^{3}$. This project incorporates creativity and crowd sourcing by using the song Ain't No Grave and very simple digital drawing tools to celebrate and commemorate the life and legacy of Johnny Cash. Fans were invited to reinterpret one single frame of the video by drawing a digital portrait of the man as they saw him and submitting it to become part of a collective video. When amalgamated this embodied a kind of haunting but also touching tribute, with many individual interpretations of Cash. Fans are using their personal experience of Johnny Cash as a way of extending his agency and confirming his meaning in their lives. However, it is the collective nature of the memorial in combination with the song that creates a pluralistic understanding of Cash.

In both Petitioning Death: Reinstate Terry Pratchett and The Johnny Cash Project a simple way of interacting with the digital medium contributes to a more substantial whole that confirms the presence of these public figures. It is the network of fans in combination with the digital medium and the translated identity of these figures, that shows how a durable biography uses collective creativity to construct agency. These practices extend the presence of the dead and visibly create a network of human and non-human players (Latour, 2005).

\footnotetext{
${ }^{3}$ The Johnny Cash Project: http://www.thejohnnycashproject.com/ [Accessed: May 20th 2018]
} 
Active forms of writing and drawing contribute to continuing bonds with these two public figures that extend their presence - creating and subverting new rituals and platforms online.

\section{From Legacy to Agency: Interacting with the Dead}

Within this paper encounters with digital, physical and hybrid things create new ways of exploring how design research can be activated through digital legacy. Using a lens of things and agency to explore specific examples, it contributes to the growing body of research that complicates the agency of the deceased. This perspective develops new modes of understanding how a person can be expanded creatively through their things, developing collective experiences that embody people.

Physical things, such as the thimbles aim to refocus our understanding, moving beyond social relations and focusing on the materiality of the digital, whose values are predominantly constructed through its form of usage rather then semiotic values. This allows designers to explore how the affordances of physical and digital materials are providing new structures and containers for embodying the dead. Breaking down the boundaries between artifacts, structures and processes allows designers to take up new challenges. That include a deeper understanding of how the things they make affect the networks they exist in, creating alternative ritual interactions that network the agency of the dead. These networks give us new ways to think through things.

Digital memorials also extend the public's consciousness. People are able to creatively use and subvert digital networks and games. This creates collective durable biographies that allow various forms of agency to manifest through the nature and function of digital platforms. In combination, the analysis of these systems allows researchers to explore how human and non-human actors may construct posthumous meaning. People may relate to the dead through a range of physical and digital things that highlight the plurality of bereavement and construct new forms of agency. 


\section{References}

Brown, B., (ed.) (2004). Things. Chicago: University of Chicago Press.

Brubaker, J.R. and Hayes, G.R., (2011), March. We will never forget you [online]: an empirical investigation of post-mortem myspace comments. In Proceedings of the ACM 2011 conference on Computer supported cooperative work (pp. 123-132). ACM.

Duncan, A. L. (2008). Political Satire in Terry Pratchett's Discworld (Doctoral dissertation, Elon University). Retrieved from http://elonuniversity.contentdm.oclc.org/cdm/ref/collection/p15446coll7/id/115

Ellis Gray, S., (2012). The diversity of mourning practices online. Digital Futures.

Freud, S., (1922). Mourning and melancholia. The Journal of Nervous and Mental Disease, 56(5), p.543-545.

Friedman, K and Stolterman, E. (2014). 'Series Foreword'. In Simonsen, J., Svabo, C., Strandvad, S.M., Samson, K., Hertzum, M. and Hansen, O.E (eds) Situated Design Methods. MIT Press.

Garde-Hansen, J., (2009). MyMemories?: Personal digital archive fever and Facebook. In Save as... Digital memories (pp.135-150). Palgrave Macmillan UK.

Getty, E., Cobb, J., Gabeler, M., Nelson, C., Weng, E. and Hancock, J., (2011), May. I said your name in an empty room: Grieving and continuing bonds on Facebook. In Proceedings of the SIGCHI Conference on human factors in computing systems (pp. 997-1000). ACM.

Giaxoglou, K., (2014). "RIP man... u are missed and loved by many”: entextualising moments of mourning on a Facebook Rest In Peace group site. Thanatos, 3(1), pp.10-28.

Gibbs, M.R., Carter, M. and Mori, J., (2013). Vile Rat: Spontaneous Shrines in EVE Online. In Workshop Proceedings of the 8th International Conference on the Foundations of Digital Games. May (pp. 14-17). 
Harper, R., (2010). Texture: human expression in the age of communications overload. MIT.

Haverinen, A. (2014). Memoria Virtualis: death and mourning rituals in online environments. (Doctoral dissertation, University of Turku). Retrieved from http://www.utupub.fi/handle/10024/98454

Heidegger, M. (Trans). (1971). "The Thing" in Poetry, Language, Thought. Translated by Albert Hofstader. HarperCollins Publishers Inc.

Henare, A., Holbraad, M. and Wastell, S. eds., (2007). Thinking through things: Theorising artefacts ethnographically. Routledge.

Ingold, T., (2013). Making: Anthropology, archaeology, art and architecture. Routledge.

Irwin, M.D., (2015). Mourning 2.0 - Continuing bonds between the living and the dead on Facebook. OMEGA-Journal of Death and Dying, 72(2), pp.119-150.

Karana, E., Giaccardi, E., Stamhuis, N. and Goossensen, J., (2016), June. The Tuning of Materials: A Designer's Journey. In Proceedings of the 2016 ACM Conference on Designing Interactive Systems (pp. 619-631). ACM.

Kasket, E., (2012). Continuing bonds in the age of social networking: Facebook as a modernday medium. Bereavement Care, 31(2), pp.62-69.

Kimbell, L. and Street, P.E., (2009), September. Beyond design thinking: Designaspractice and designs-in-practice. In CRESC Conference, Manchester . [Online]. Available: http://www.lucykimbell.com/stuff/CRESC Kimbell_v3.pdf

Kirk, D. and Sellen, A., (2008). On human remains: Excavating the home archive. Microsoft Research, Cambridge, UK.

Klass, D., (2006). Continuing conversation about continuing bonds. Death Studies, 30(9), pp.843-858. 
Klastrup, L., (2015). “I didn't know her, but...”: parasocial mourning of mediated deaths on Facebook RIP pages. New Review of Hypermedia and Multimedia, 21(1-2), pp.146-164.

Lange-Berndt, P. ed., (2015). Materiality. Co-published: Whitechapel Gallery and MIT Press.

Latour, B., (2004). Why has critique run out of steam? From matters of fact to matters of concern. Critical inquiry, 30(2), pp.225-248.

Latour, B., (2005). Reassembling the social: An introduction to actor-network theory.

Oxford university press.

Latour, B., (2008). A cautious prometheus? A few steps toward a philosophy of design (with special attention to Peter Sloterdijk). In Proceedings of the 2008 annual international conference of the design history society (pp. 2-10).

Malafouris, L., (2013). How things shape the mind. MIT Press.

Marwit, Samuel J., and Dennis Klass. "Grief and the role of the inner representation of the deceased." Omega-Journal of Death and Dying 30, no. 4 (1995): 283-298.

Massimi, M., \& Baecker, R. M. (2010, April). A death in the family: opportunities for designing technologies for the bereaved. In Proceedings of the SIGCHI conference on Human Factors in computing systems (pp. 1821-1830). ACM.

McCarthy, J., Wright, P., Wallace, J. and Dearden, A., (2006). The experience of enchantment in human-computer interaction. Personal and ubiquitous computing, 10(6), pp.369-378.

McCullough, M. (1998). Abstracting craft: The practiced digital hand. MIT press.

Miller, D., (2008). The comfort of things. Polity.

Miller, D., (2010). Stuff. Polity.

Moncur, W. and Kirk, D., (2014) An emergent framework for digital memorials. In Proceedings of the 2014 conference on Designing interactive systems (pp.965-974). 
ACM.

Moncur, W., Julius, M., Van Den Hoven, E., and Kirk, D., (2015). Story Shell: the participatory design of a bespoke digital memorial. In Proceedings of 4th Participatory Innovation Conference (pp.470-477).

Odom, W., Harper, R., Sellen, A., Kirk, D. and Banks, R., (2010). Passing on \& putting to rest: understanding bereavement in the context of interactive technologies. In Proceedings of the SIGCHI conference on Human Factors in computing systems (pp.1831-1840). ACM.

Pitsillides, S., (2017) Digital Death: The Materiality of Co-crafted Legacies. (Doctoral dissertation, Goldsmiths, University of London). Retrieved from: http://research.gold.ac.uk/22959/

Richardson, A., (2005). New media, new craft. In Proceedings of the International Conference on Computer Graphics and Interactive Techniques (p.157-159).

Romano, J., (2011). Your Digital Afterlife: When Facebook, Flickr and Twitter Are Your Estate, What's Your Legacy? New Riders.

Sanders, E.B.N. and Stappers, P.J., (2008). Co-creation and the new landscapes of design. Co-design, 4(1), pp.5-18.

M Schwartz, M. (2015). Dead matter: The meaning of Iconic corpses. University of Minnesota Press.

Telier, A., (Binder, T., De Michelis, G., Ehn, P., Jacucci, G., Linde, P. and Wagner, I.,) (2011). Design Things. The MIT Press.

Turkle, S., (2011). Evocative objects: Things we think with. MIT press.

Uriu, D., and Okude, N., (2010), August. ThanatoFenestra: photographic family altar supporting a ritual to pray for the deceased. In Proceedings of the 8th ACM Conference on 
Designing Interactive Systems (pp.422-425). ACM.

Wallace, J. (2007). Emotionally charged: A practice-centerd enquiry of digital jewellery and personal emotional significance. (Doctoral dissertation, Sheffield Hallam University). Retrieved from http://citeseerx.ist.psu.edu/viewdoc/download?doi=10.1.1.467.1168\&rep=rep1\&type=pdf

Wallace, J. and Press, M., (2004). All this useless beauty: the case for craft practice in design for a digital age. The Design Journal, 7(2), pp.42 - 53.

Walter, T., (1996). A new model of grief: Bereavement and biography. Mortality, 1(1), pp.725

Walter, T., (2008). The presence of the dead in society. In Conference on Death \& Dying in 18-21c Europe , Alba Iulia, Romania.

Walter, T., Hourizi, R., Moncur, W. and Pitsillides, S., (2012). Does the internet change how we die and mourn? Overview and analysis. OMEGA-Journal of Death and Dying, 64(4), pp.275-302.

Walter, T. (2013) Do modern societies comprise the dead as well as the living? CDAS Working Paper Series - CDAS-001-0113. [Online] Available:

http://www.bath.ac.uk/cdas/documents/cdas working paper cdas-001-0113.pdf 